\title{
Technical distance learning lecturer
}

\author{
M.M. Burkina ${ }^{1 *}$ \\ ${ }^{1}$ Scientific Center for Robotics and Technical Cybernetics, Saint Petersburg, Russia
}

\begin{abstract}
At the present time, a range of educational services to provide distance learning technologies characterized by a huge number of students, a lot of involved educational institutions, the big size and complexity of infrastructure, the large scale of funding, the connection of high-tech services, and many others has been developed in the world. Intensely penetrating all levels of the modern education system, distance learning technologies are a leading tool for improving the education system in higher education implemented in connection with changes in its goals and content, improving the quality and accessibility for various categories of people.
\end{abstract}

\section{A problem statement}

In the $21^{\text {st }}$ century, society faced such problems as rapid change of information flows, economic instability. Many professions have been becoming obsolete in the labor market, so employees in these areas are forced to change the scope, content, and quality of their knowledge and skills in the process of rotation, or acquire them anew adapting to a new professional field. New professions have been emerging, they require the rapid response of the education sector to fill the expanding nomenclature vacuum.

Nowadays the demand for distance education in Russia is estimated to be commensurate with the needs of full-time education, i.e. approximately 1.5 million students per year. The Russian-speaking population in foreign countries and people for whom Russian is the second main language have been becoming major consumers of the distance education system. The demand for distance learning is also due to the need to implement the principle of openness of education, to expand the rights of individuals to receive education in the educational institution that the future specialist seems more attractive. Currently, distance education is considered as a form of education that allows you to choose training courses and is a promising way to get education in remote areas from educational centers.

The growth of "knowledge-intensive" production has recently led to an aggravation of the problem of training highly qualified personnel in higher education institutions in the country. Anticipating the emergence of certain difficulties, the leadership of higher education institutions has already taken measures that will significantly simplify the solution of this problem in the future: further improvement of "classical" forms of student education; development of modern pedagogical technologies, including those in distance learning of students.

\footnotetext{
* Corresponding author: ipcs-profped@yandex.ru
} 
Along with traditional correspondence and full-time forms of education in higher education institutions around the world, the system of "virtual institutes" has recently begun to be actively implemented [1-3], which allows students to study using information technologies not only in the educational institution, but also at work, at home or in dispersed training centers. The introduction of "virtual institutes" is due to the growing demand for highly qualified personnel in connection with the increase in the "knowledge intensity" of modern production. The technical prerequisite for the possibility of existence is the development of a digital educational environment.

\subsection{The objective of the work}

The research is based on modern foreign and domestic concepts on the problems of distance education, materials of sociological research. We used data from statistical studies and official documents of the Ministry of education of the Russian Federation.

The results of a preliminary analysis of the literature indicate that any computer (digital) learning system should be based on a clear model of presentation and organization of educational material, and the development of systems of this class should be carried out within a single methodological approach $[4,5,6,7]$.

We present the relationship and interaction of scientific approaches to solving the problem under study, namely:

Environmental approach (S.A. Gorshenin, S.A. Ivashchenko, I.V. Ignatovich, Yu.S. Manuilov, G.G. Shek), on the base of that an adaptive innovative environment for training a lecturer of distance learning for professional pedagogical activity at a University has developed, this approach includes indirect management of the process of developing the innovative potential of a University lecturer and represents a system of actions of subjects in an innovative educational environment focused on its formation as a means of diagnostics, design and obtaining results $[8,9]$.

Axiological approach (M.Ya. Vilensky, D.A. Gorbacheva, A.V. Kiryakova, M.I. Kryakhtunova, V.V. Moroz, L.S. Podymova, V.A. Slastenina, E.N. Shiyanov), which actualizes the motivational and value sphere of a University distance learning lecturer as a driving force for the development of personal and professional qualities, where innovative potential acts as an element of human capital, where mastering innovative learning tools for a University lecturer will serve as a core of pedagogical freedom, personal autonomy and professional success, creating conditions for the development of innovative potential and disclosure of the innovative personality of a University lecturer [10].

Acmeological approach (K.A. Abulkhanova-Slavskaya, B.G. Ananyev, A.A. Volumes, A.A. Derkach, I.L. Lapteva, T.A. Polozova, N.A. Rybnikova), within the framework of that the process of achieving the highest degree of professionalism and manifestations of innovation potential of personality of a lecturer of distance learning at a University, as well as the achievement of individual peaks of self-realization and professionalism (professional identity; continuous improvement; actively seek development opportunities; modeling of the pedagogical position and innovative future in professional pedagogical activity are studied. Through the prism of the acmeological approach, T.A. Polozova focuses on the study of mental, psychological, social, socio-cultural, spiritual changes, transformations and new formations that occur in a lecturer as an individual, subject, and ipersonality in the process of mastering the teaching profession and performing professional activities in all possible forms, at all levels and in different conditions. Basic elements of the innovative potential of a University lecturer based on the acmeological approach: activity in innovative behavior, thinking and development; professional self-improvement of a University lecturer (up to the formation of innovative skills, achievement of professional Acme); innovative 
self-development and self-education of a University lecturer, development of a unique personality and innovation [11].

Competence-based approach (D.Yu. Anufrieva, I.A. Zimnaya, N.V. Kuzmina, V.V. Kraevsky, A.K. Markova, L.M. Mitina et al.), focused on the University's distance learning lecturer's mastering competencies for solving professional problems in innovation (a combination of innovative knowledge, innovative skills and ideas, innovative values and inclinations, innovative actions and processes, innovative relationships, innovative experience) and the professional position of the University lecturer as an integrative interaction with personal qualities, updating innovative abilities in action, it determines the effectiveness of achieving the optimal level of the lecturer's development and preparation for professional activity, reflects the readiness of the University lecturer for professional growth, mastering the techniques of self-realization to new types of professional pedagogical activity. The competence approach from the point of view of I.A. Zimnaya can be viewed from the angle of various aspects: cognitive - which includes innovative knowledge of professional pedagogical activity; behavioral - which will include innovative abilities and professional experience in a variety of standard and non-standard situations, pedagogical activities of University lecturers; axiological - reflecting the value attitude to the content and outcomes of innovative educational activities; regulatory - reflects the emotional-volitional regulation of process and outcome of professional pedagogical activities; motivational - reflects the readiness to actualize the manifestation of innovative abilities of a University lecturer in various situations of solving social and professional problems [12-13].

\section{Materials and the results of the research}

Expansion of the information educational and scientific-pedagogical field by attracting international experience in creating special computer technologies; intensification of integrative processes in the development of foreign economic relations; Russia's entry into the world economic and educational space set the following goals and objectives:

Objective: to provide a theoretical justification of the pedagogical conditions for implementing distance learning in a knowledge-intensive educational environment.

Tasks:

Training distance learning lecturers in a modern knowledge-intensive environment.

To determine the features of learning in the distance learning system.

To identify and justify the pedagogical conditions that contribute to the implementation of distance learning in a knowledge-intensive educational environment, taking into account the features of learning in a digital environment. The methodological basis of the research consists of: philosophical concepts of personal activity; general aspects of management theory; system, synergetic, cybernetic, personality-oriented, competence-based approaches to the problem of distance learning in higher education.

The implementation of the ideas of "virtual institutes" is a process of continuous education of technical specialists, which requires adaptive selection of the material used. The adaptability of educational resources is that the content and / or form of presentation of the material depends on the characteristics of the user. The essence of adaptation is the ability to "adapt" the level of knowledge of the student and his preferences to the learning goals. A prerequisite for this is the development of an adaptive hypermedia training course, i.e. a course in which the organization of the material is made in the form of hypertext using multimedia capabilities, i.e. educational and methodical complex.

Distance learning was first mentioned in 1850, when the Institute of distance education was established in Russia. At the present time, the number of distance learning institutions of various types and levels in the world has exceeded 1,100. In a number of countries 
(China, Latvia, the Netherlands, Algeria, Great Britain, Turkey, etc.), the share of students receiving education remotely ranges from 10 to $25 \%$, and, for example, in the Republic of Korea, $83 \%$ of universities have implemented a distance learning system, which has put the country among the world leaders in the use of information and communication technologies in education [2].

The University of Pennsylvania (Penn State University) is now recognized as one of the most authoritative in the field of distance education. The experience of the University was used by UNESCO in creating the concept of a virtual University. Distance education business programs account for $25 \%$ of all distance education programs in America. Companies such as General Motors, J.C. Penny, Ford, Wal-Mart, and Federal Express provide staff training through private corporate educational networks. The internal satellite educational network is used by IBM for this purpose.

The introduction of distance learning in the higher education system allows to reduce the cost of training, expand the number of trainees, as well as personalize the approach to each student (the student himself determines when and how to study the proposed material), and so on. Using special distance learning systems, students can directly contact experts anywhere in the world, as well as study their lectures recorded on various media, use electronic libraries, and so on [14]. The DL system relies on a variety of media for both content transmission and interaction. The restrictions imposed are due to factors such as the degree of accessibility and use of media for students, the level of competence of lecturers in the use of information tools for the development and presentation of educational material, the financial capacity of universities, as well as the local and national communication infrastructure that supports these media.

Currently, the main technologies of distance learning are the following:

Case technology is a remote educational technology based on providing students with educational information resources in the form of specialized sets of educational and methodological complexes designed for self-study using various types of information carriers.

Internet technology (network technology) is a remote educational technology based on the use of global and local computer networks to provide students with access to information educational resources and to form a set of methodological, organizational, technical and software tools for implementing and managing the educational process, regardless of the location of its subjects.

Telecommunications (information and satellite) technology is a distance learning technology based on the use of satellite data transmission and television broadcasting, as well as global and local networks to provide students with access to educational information resources presented in the form of digital libraries, video lectures, etc.

All these technologies should be considered as the result of the addition of more elementary distance learning technologies. The classification feature of this division of technologies is mainly the method of delivering educational material from the educational institution to the student and the results of his feedback. As a rule, none of these technologies is used in its pure form, but each one is implemented together with elements of other distance education technologies. Along with the term "distance learning" in the literature, the term "open and distance learning" is often used, emphasizing the fact that compared to traditional learning, distance learning is open to a wider audience. Open learning does not involve entrance exams and is available to anyone; moreover, it can be "informal" (nonformal, informal learning), i.e. it does not end with obtaining the relevant educational documents. Recently (since the 1990s), due to the development of information and communication technologies, distance learning has gained a "second wind" in the form of electronic learning, e-learning (EE). At the same time, it should be emphasized that the introduction of information technologies in the educational process does not exclude the 
use of traditional printed materials, direct communication with the teacher (including via TV or video conferences), etc.

A systematic approach to the problem of distance learning has made it possible, using elearning methods, to increase its effectiveness by introducing into practice software systems that provide a comprehensive solution to learning problems. These systems include: learning content management systems, systems for delivering learning materials "at the right time in the right quantity to the right place", testing systems, competence management subsystems for tracking learning outcomes, interactive support systems for the learning environment, knowledge management systems, learning management systems [15-16].

It should be noted that e-learning methods are used not only by educational institutions, but also by large corporations interested in improving the educational level of their employees. For example, Microsoft uses similar approaches to the use of information technologies in education, combining them under the term Connected Learning Community (CLC). The CLC concept is a simple but powerful combination of information technologies in education, the best methods of traditional learning, and a new understanding of the learning process itself. According to this concept, the world is a constantly updated learning environment in which the use of information technologies expands learning opportunities providing the necessary practical experience of their implementation. The distinctive features of the modern approach to e-learning are: complexity, consistency (comprehensive coverage of target groups, systematic solution of issues related to the organization and provision of e-learning); emphasis on the development of modern pedagogical technologies based on the information educational environment (problem-based and project-based training, training in collaboration, etc.); dynamically changing structures; process management; knowledge management in e-learning processes and its provision.

Distance learning technology has become widely used in the educational process of higher education institutions and research institutes.

The students consider as the main advantages of distance learning: flexible schedule and pace of the educational process $(87.3 \%)$; the ability to combine training and work $(73.2 \%)$; technological process $(53.8 \%)$; getting practical skills $(41.7 \%)$; learning in a comfortable and familiar environment $(57.1 \%)$; ease of updating content and archiving old material (33.5\%); time savings (38.7\%) and cost savings (46.2\%). And only $5.7 \%$ of respondents said that " they do not see any advantages in distance learning." The main difficulties that students face in distance learning are the lack of direct face-to-face communication with the lecturer $(37.5 \%)$; problems related to the complexity of the course content $(27.3 \%)$; insufficient quality of distance material $(13.8 \%)$. The data obtained indicate that distance learning is in demand among modern youth, but still requires a lot of work to improve the technical and theoretical base.

According to the results of the survey, the following are named as the optimal ways of educational interaction with the lecturer: webinar $-46.4 \%$; forum $-39.1 \%$; video services (Openmeetings, Skype) - 32.2\%; practical work presented in digital form, with feedback from the lecturer $-29.5 \%$; individual consultations $-30.6 \%$ : a combination of tools: screen translation, group chat and audio conference, joint documents in GoogleDocs $-41.5 \%$; email $-13.7 \%$. Of course, the use of information technologies in education is more attractive for modern students than traditional forms of education.

In general, $88.2 \%$ of students are satisfied with the use of distance learning technology in the educational process, and only $11.8 \%$ of respondents expressed dissatisfaction with distance learning.

The results of the survey showed that respondents, conducting a heuristic assessment of the effectiveness of distance learning, note the fact that the DL has such a disadvantage as the lack of direct "live" communication "lecturer - student" during the study of the last educational material. Part of this problem can be solved by using mixed learning, which 
combines e-learning methods and traditional classroom teaching in full-time mode, since "purely electronic" learning reduces the volume and quality of laboratory research performed by students, i.e. reduces the share of the "practical component" of their training.

In the pedagogical literature, we can observe a mixture of the concepts of "distance learning lecturer "and" tutor", without emphasizing the differences between the activities of a lecturer in a digital educational environment and a tutor [18].

The digital educational environment is full of information, it represents a kind of pedagogical potential, through the use of which the tutor creates and supports hope, first trying to assume the aspirations of the one who studies, then "throwing" information to him, due to which his motivation finds food, is strengthened and stimulated [19].

The terms "remote teacher" was introduced by A.V. Khutorsky in 1999 [20].

A review of subsequent research papers in the field of requirements for training a teacher to work in the distance learning system (DL) showed a large number of diverse approaches to the formulation of competencies and description of requirements for the activities of a distance teacher [21].

A teacher who performs the functions of a tutor is defined by us as a specialist who works to create conditions for the development of students by organizing personal support in the educational space of an educational institution, advising students in the process of self-education, mentoring in the process of personality formation and motivation for selfdevelopment.

In this study, the division of functions between the organizers of the educational process in the digital educational environment is significant for us: lecturers, tutors.

The role of the lecturer is to train students using modern tools and technologies; the role of the tutor is to support the student in the process of learning the curriculum and the direction of movement along the trajectory of professional growth; the role of the administrator is technical support, ensuring optimal conditions for the functioning of the digital educational environment.

Based on this understanding of the role of the lecturer, in terms of the goals of our research, it is necessary to compare him and the lecturer of the traditional learning system. This comparison will allow us, on the one hand, to determine the requirements for a lecturer who trains lecturers for innovation, on the other hand, to outline the qualification "Delta" that teachers themselves must overcome during this training.

The activity of a lecturer in a digital educational environment is characterized by indirect communication during training, using the means of the digital educational environment to search for and deliver educational materials, implement feedback with the student, provide support, correct and direct the student's work, and strive for cooperation, taking into account the student's motivation.

These features determine the content of the teacher's activity in the digital educational environment, its role, function, and requirements.

An important part of innovative online learning is active independent work of the lecturer. A feature of learning in a digital educational environment is the lack of constant face-to-face contact with the lecturer, which obliges the student to independently build their own educational process. Therefore, the role of the lecturer is not so much in the transfer of knowledge, but in the organization of cognitive activity and the direction of creative activity of the student [22].

At the same time, the lecturer's activity in the digital educational environment is diverse. To work in such an educational environment, the lecturer needs to master new types of professional activities and roles that were not typical for him before:

- the author and developer of the e-learning course;

- the lecturer as the organizer of the educational process; 
- the consultant who organizes professional pedagogical support in the course of training and post-course training;

- the organizer of joint activities of students;

- the psychologist who creates comfortable conditions for learning; the designer of the educational process (designs the forms of organization of the educational process and activities that most correspond to the goals and content of the course being studied, often their own course);

- the colleague and employee (this function is especially pronounced when teaching innovation activities using a digital educational environment aimed at professional lecturers);

- the student in the course of the pedagogical process, since self-learning and mutual training of the lecturer and the student is an attribute feature of innovative learning within the open model of continuing education.

The functions of a lecturer in a digital educational environment coincide with the functions of a lecturer in traditional education, differing in the specifics of implementation.

\section{Conclusions}

Based on the experience gained as a result of the research and based on educational standards, we believe that the general requirements for the qualification characteristics of a lecturer are preserved and specific requirements for working in a digital educational environment are added to them.

Thus, the successful preparation of traditional teaching staff for professional activities in the digital educational environment and adaptation to the new functional responsibilities of the lecturer are possible with a radical revision of the requirements for their teaching activities.

The study clarified the difficulties of implementing a new type of professional activity of the organizers (lecturer, tutor) of the learning process in the digital educational environment:

- Lack of trained specialists to organize training in a digital educational environment. As a result, there is a need for continuous education of both lecturers and students, preparing them for innovative activities in a "virtual Institute".

- The need to systematically update the content of training in connection with constant changes in the modern world. This determines the mobility of the lecturer, his internal tolerance-readiness to accept changes in the external world.

- Reorientation to new types and environments of activity: adaptation from the point of view of solving technical, methodological and professional problems of pedagogical activity.

- Increasing the load on the lecturer during the preparation, development of classes, teaching materials, and didactic tools. During the period of modernization of education, introduction of innovative technologies, the content of training courses requires systematic updating and serious improvement.

A distance learning lecturer who has and uses in the educational process distance learning technologies can achieve the best quality in the professional training of future technical specialists. Individualization and differentiation of training will help to develop professional skills and creative abilities of students, which will increase the level of preparedness of graduates of educational institutions.

Today, the need for specialists who can work with a dynamic information environment exceeds the ability of the educational system to train them. This has led to the fact that education has been considered as the most important factor in economic growth and social development of countries, solving a number of global problems. 


\section{References}

1. O.L. Borisyuk, Innovative activity as a resource for the quality of education of a University student. - Konf. Minsk p. 28-32 (22-23 Dec. 2011)

2. History of distance learning: http://e-college.ru/elearning/main-dl/history.html

3. E.M. Tyurikova, Humanitarian vector, 1, 72-76 (2013)

4. N.N. Kuzmina, Universities as centers of innovative development scientific discussion: actual scientific problems of the XXI century. Anniversary collection of scientific papers of young scientists and students of the SUSU International faculty, dedicated to the 20th anniversary of the faculty. (Chelyabinsk: SUSU publishing center, 116-119, 2016)

5. T.V. Vergun, Modern science-intensive technologies, 8, 99-100 (2008)

6. N.V. Nikulicheva, Model of a distance learning course for training a distance learning teache, 3 (59) 54-60 (Tomsk, Open and distance education 2015)

7. J.A. Lesquin, World of science, culture, education, 2 (57), 217-220, (2016)

8. S.A. Ivashchenko, Environmental approach as a means of improving the quality of education of teachers-engineers Innovative processes in education: strategy, theory and practice of development: Materials of the VI all-Russian scientific and practical conference, 1, 162-164 (Yekaterinburg, 2013)

9. K.N. Volchenkova, Bulletin of the South Ural state University, 7, 18-25 (2015)

10. T.Yu. Gvildis, Man and education, 1 (50), 40-45. (2017).

11. I.A. Zimnaya, Competence and competence in education (Eidos, 2014)

12. N.A. Markova, Young scientist, 9 (89), 1126-1129 (2015)

13. T.Yu. Gvildis, Criteria for personal and professional development of the modern teacher (Man and education, Saint Petersburg, 2017)

14. T.Yu. Gvildis, Current models and effective practices in the preparation of scientificpedagogical personnel in Russia and abroad, Problems of modern pedagogical education (Yalta, 2016)

15. N.R. Kurkina, L.V. Starodubtseva, Modern high-tech technologies, 11-1, 220-224 (2019)

16. S.M. Avdeeva, A.Yu. Uvarov, Science and school, 6, 146-157 (2016)

17. O.G. Smolyaninova, E.A. Bezyzvestnykh, Teacher of the XXI century, 1-1, 135-148 (2017)

18. T.I. Krasnova, Young scientist, 7, 793-795 (2015)

19. A.V. Khutorskoy, Open education, 2, 30-35 (2001)

20. N.B. Sekulich, Bulletin of BSU, 4, 114-120 (2016)

21. I.V. Mironova, International research journal, 3 (45), 25-27 (March 2016) 